\title{
Beyond the Capstone: National Competition and Community Engagement in A Timber Bridge Senior Project
}

\section{Dr. Bin (Brenda) Zhou P.E., Central Connecticut State University}

Dr. Zhou is an Associate professor in the Engineering Department at Central Connecticut State University (CCSU). Her research enthusiasm lies in quantitative analyses and modeling techniques, and her field of expertise is transportation planning and engineering. After joining CCSU, she expanded her work into STEM education, student outreach, and community engagement.

\section{Sylwia Tanski, Fuss \& O’Neill, Inc.}

Sylwia is a Civil Engineer working in the Comunity Development Department at Fuss \& O'Neill. Equipped with a Bachelor's degree in civil engineering and Master's degree in land and real estate management, she plans to focus her professional career on sustainable and human-scaled urban design. 


\section{Beyond the Capstone: National Competition and Community Engagement in A Timber Bridge Senior Project}

\section{Introduction}

A capstone course is an integral part of Civil Engineering (CE) undergraduate education. It requires graduating students to apply knowledge and skills gained from courses in a $\mathrm{CE}$ curriculum in a design that mimics 'real world' projects. The scope and level of detail in senior projects can vary noticeably. This paper presents a senior design project in which a group of five students built a pedestrian timber bridge for a local community and participated in the 2019 National Timber Bridge Design Competition.

This project was one of eleven civil engineering senior design projects for the 2018-2019 academic year in the two-semester 2-credit senior design class at Central Connecticut State University (CCSU). This project combined a design build project with a national competition and required an innovative approach to project management from the participating students and advising faculty. A substantial part of this senior project, not traditionally seen in other capstone projects in a relatively new ABET accredited CE program, consisted of finding a location for the bridge, fundraising and budgeting funds, coordinating with outside agencies, purchasing materials, and constructing a pedestrian timber bridge.

The project team had to learn competition specifications, design criteria, and test procedure, in addition to all the engineering aspects of a timber bridge project. Moreover, during the capstone project initiation/selection phase, the project team determined to donate the bridge to a local community, which inevitably brought in more design constraints and time-consuming tasks. The project team took roughly eight months to complete this first-of-its-kind capstone since our ABET accredited CE program began about ten years ago.

Time management and teamwork were paramount to the success of this senior project. In addition to this "multi-dimensional" project, each participating student was taking about 14 credits per semester and was required to take the Fundamentals of Engineering (FE) exam before finishing the capstone course. All five team members were commuter students; two maintained part-time jobs, and two served as key officers to the American Society of Civil Engineers (ASCE) student club throughout this time. Each student took on a unique element of this project based on his/her interests and strength, and supported each other when a task was discovered to be more demanding than expected or falling behind schedule. In addition, one student served as the "captain", and coordinated all aspects of this project while working closely with the faculty advisor. Teamwork was undoubtedly important, but leadership among participating students was essential to the success of a senior project like this.

Three faculty members made meaningful contributions to this senior project, using their technical expertise and unique skills. One structural engineering professor assisted students with 
structural preliminary design using SAP 2000; one professor with background in timber structures supervised students in structural final design and joint design; one faculty advisor took care of administrative aspects of this project, such as funding, project schedule, weekly meetings with students, coordination with outside entities, etc. The faculty advisor also made sure design criteria and test procedures were followed, ensuring a successful entry to the National Timber Bridge Design Competition. This faculty advisor was the lead faculty member in the overall evaluation of this project, including grade submission. Timely communications and professional consent among faculty members were critical in building a supportive environment for students to succeed. In addition, a structural engineer from the industry served as a mentor to the team, and supplemented the two structural engineering professors in the structural preliminary and final designs. The team also had a mentor with experience in wood construction.

The two objectives of this senior project were to participate in the 2019 National Timber Bridge Design Competition and build a pedestrian timber bridge for a local community. The scope of work included surveying the site, creating a topography map, structure designing and modeling, creating construction drawings, constructing the bridge, testing the bridge by competition rules, submitting competition applications, and transporting the bridge to the site. The town that received the donation prepared the site and placed the pedestrian timber bridge in its location.

\section{National Timber Bridge Design Competition}

This senior project was initiated to compete in the 2019 National Timber Bridge Design Competition. This national competition launched in 1993, and is currently coordinated by the Southwest Mississippi Resource Conservation and Development (RC\&D), Inc. It is endorsed by ASCE's Structural Engineering Institute (SEI), and is financially sponsored by Bell Structural Solutions in Minnesota. The objectives are: "to promote interest in the use of wood as a competitive bridge construction material, to generate innovative and cost-effective timber bridge design techniques, and to develop an appreciation of the engineering capabilities of wood" [1]. Student chapters of ASCE and Forest Products Society (FPS) in the United States and Canada are eligible to compete. Participating teams are required to submit applications electronically on a $\mathrm{CD}$, which contain a series of digital photos taken during construction and testing, bridge construction drawings, and a PowerPoint presentation. More details can be found at [1].

The National Timber Bridge Design Competition does not require an "actual" competition in a designated location, so no travel is required. This is very attractive for nontraditional students who have time constraints due to many other obligations and for universities/student clubs that have limited funds to support student travel.

The competition has detailed design criteria and test set-ups. The main design restrictions are as follows: 
- Allowed design span is $4.0-6.0 \mathrm{~m}(13.12-19.68 \mathrm{ft})$ from centerline to centerline of supports.

- Allowed horizontal Clearance is $1.3-1.95 \mathrm{~m}(4.27-6.3 \mathrm{ft})$ inside curb to inside curb.

- Maximum length of an individual piece in any member is $3.2 \mathrm{~m}(10.5 \mathrm{ft})$.

Please note that the team participated in the 2019 competition, but followed 2018 competition rules due to a mistake on the competition website. The competition organizer allowed the team to proceed with 2018 competition rules.

The competition specified two test loading set-ups to measure maximum vertical bridge deflection and maximum vertical net deck deflection. In both set-ups, a testing load was applied in four equal increments of $5 \mathrm{kN}$ (1124.04 Ibf), and the full load of $20 \mathrm{kN}$ (4496.17 Ibf) was achieved between 5 to 20 minutes. Deflections were recorded at each $5 \mathrm{kN}$ load increment as well as at the full load of $20 \mathrm{kN}$ (4496.17 Ibf), with each full-load reading recorded at 15-minute intervals for a duration of one hour. The project team had no access to a testing machine with such loading capacities, so the team used bags of cement to apply loads. Figure 1 shows the team's CAD drawing of the two deflection testing set-ups, and Figure 2 shows photos taken during tests.
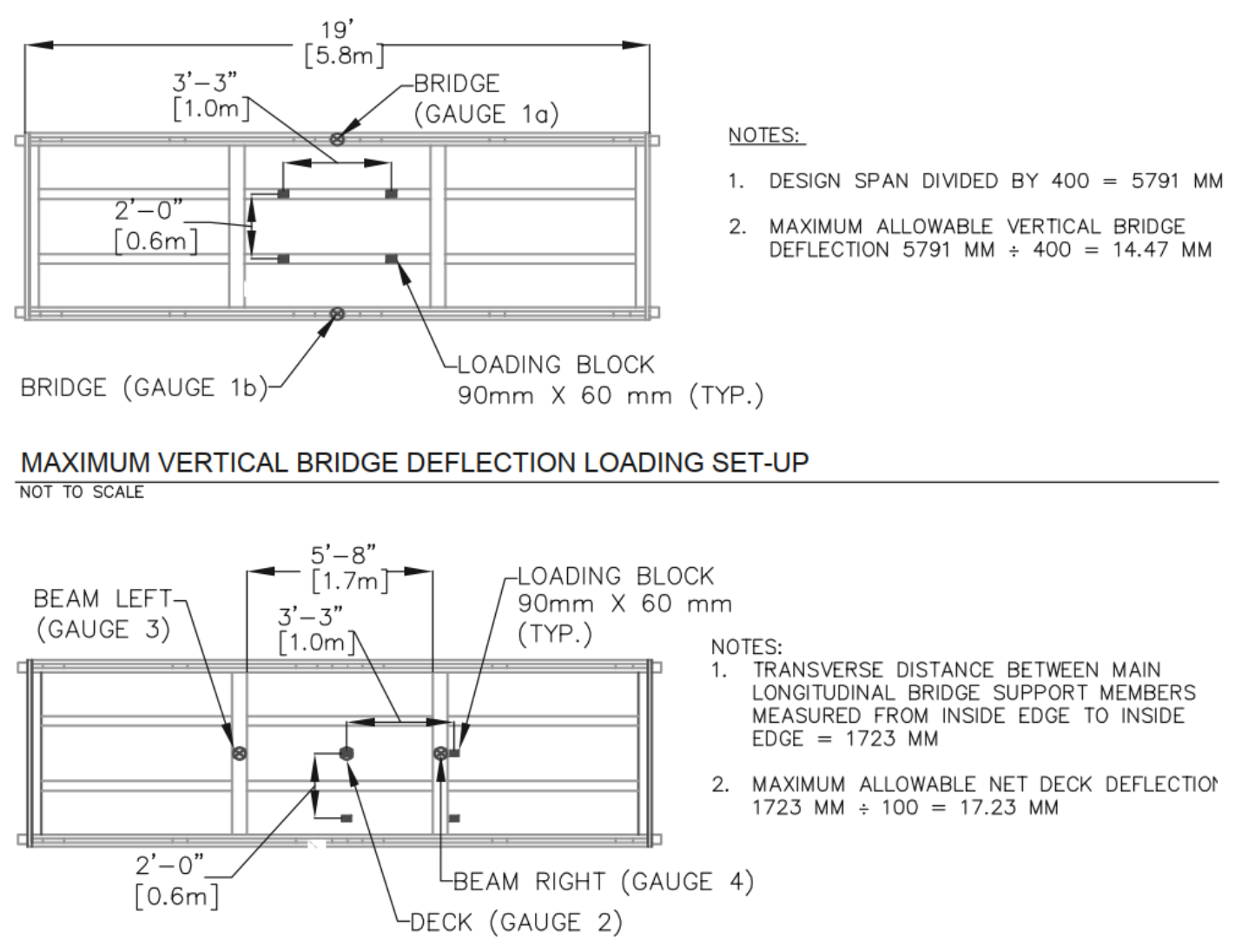

MAXIMUM VERTICAL NET DECK DEFLECTION LOADING SET-UP NOT TO SCALE

Figure 1: Deflection Test Set-up Specified by the National Timber Bridge Design Competition 

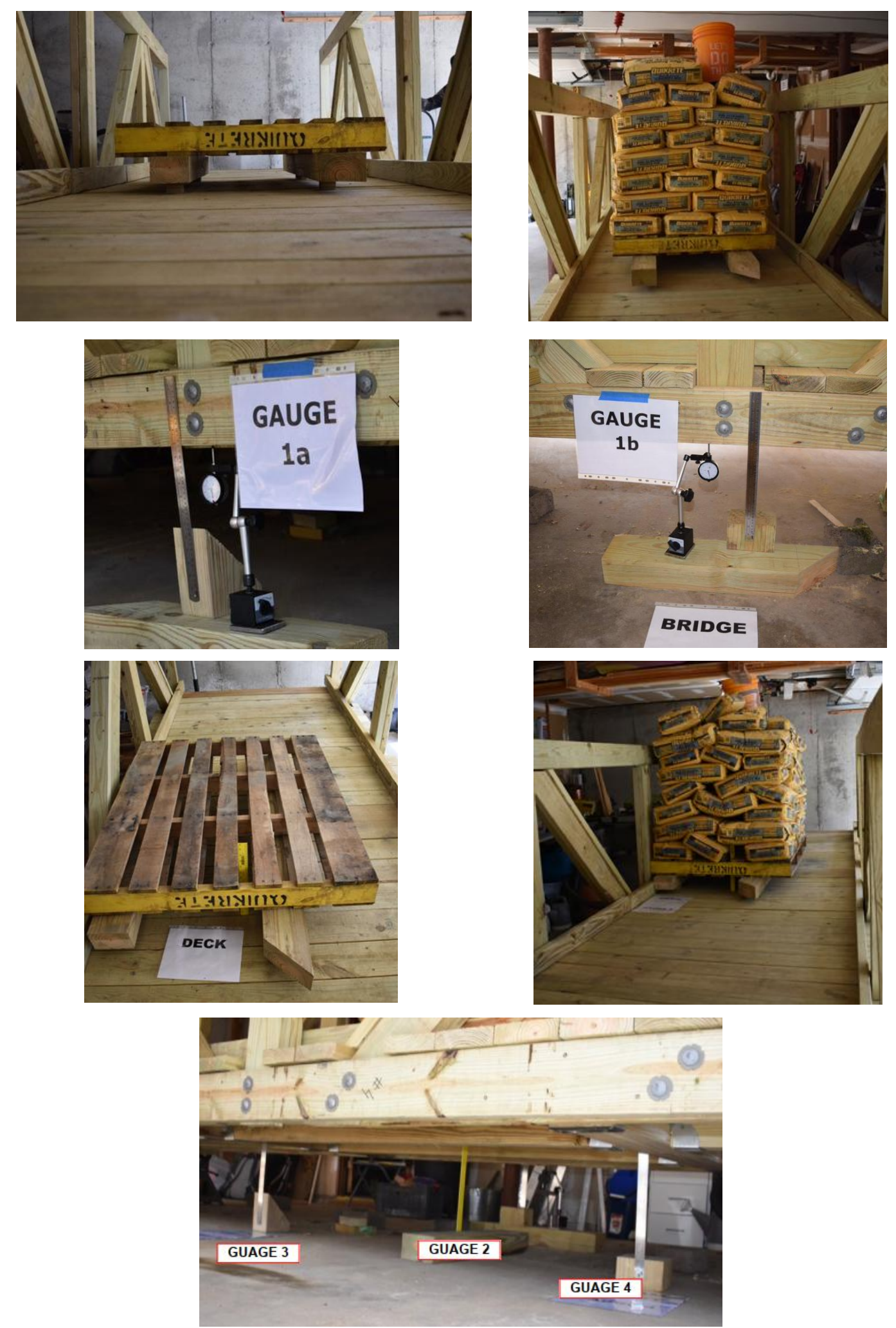

Figure 2: Deflection Test Photos

Note: Top four are for the first loading set-up (top diagram in Figure 1) and bottom three are for the second loading set-up (bottom diagram in Figure 1) 
The final vertical bridge deflection was $14.00 \mathrm{~mm}$, which is slightly lower than the maximum allowable deflection of $14.47 \mathrm{~mm}$, calculated based on bridge dimensions. The final net deck deflection was $5.25 \mathrm{~mm}$, which is noticeably lower than the maximum allowable value, $17.23 \mathrm{~mm}$. The team discovered that the total vertical bridge deflection after setting was very close to modeling outputs from the IES Visual Analysis software used in the structural final design ( $2.50 \mathrm{~mm}$ vs. $2.73 \mathrm{~mm}$ ), confirming the applicability of chosen software package and construction techniques. It is worth mentioning that maximum bridge deflection is only one element in competition scoring criteria, therefore even if measured deflection exceeds the maximum allowable value, a participating team can still submit their application and participate.

Among thirteen participating teams, this project team won second place in the Most Aesthetic Design category of the 2019 National Timber Bridge Design Competition.

\section{Design Criteria and Constraints}

In addition to the rules set by the National Timber Bridge Design Competition, other guidelines from the Americans with Disabilities Act (ADA), International Building Code (IBC), and Occupational Safety and Health Administration (OSHA) were taken into consideration. The design phase of this project started with a field survey of the site and development of a base map in AutoCAD Civil 3D. A field survey was required as the team proposed site improvements of the existing walking path and relocation of the pedestrian bridge. Survey data was used to determine optimal bridge geometry and final elevation. Proposed site improvements were approved by town officials.

The team proposed two preliminary designs with different structure configurations and modeled them using SAP2000. The design with a smaller deflection was chosen for further analysis, because deflection was a major scoring criterion in the competition. The team then developed the final structure through an iterative design process over the course of two months using IES Visual Analysis modeling software. The final design was based on two trusses distributing loads through different beams, and the trusses also served as guardrails required for pedestrian bridges in public parks.

The national competition specifies design span, horizontal clearance, vertical clearance, and depth of understructure in terms of ranges or maximum values, which provides enough flexibility for the project team to design a suitable bridge for a chosen site. However, due to constraints imposed by the site, the bridge was on the longer and wider side of the specification spectrum, which might have negatively impacted deflection testing results and competition outcome. Among thirteen participating teams, the bridge was the second heaviest and deflected $96.7 \%$ of the allowable amount (only smaller than one entry).

According to IBC regulations, the railing system was initially designed to have 4 in. spacing between intermediate rails. However, during the construction phase, the IBC railing system proved to be complicated and time-consuming, and thus was replaced with an OSHA 
based railing system recommended for "remote and low-risk areas". Figure 3 shows the initial and final railing system designs. The final railing system was reviewed and approved by officials from the town. Figure 4 shows the final pedestrian timber bridge reassembled on a parking lot and to be placed at its location.

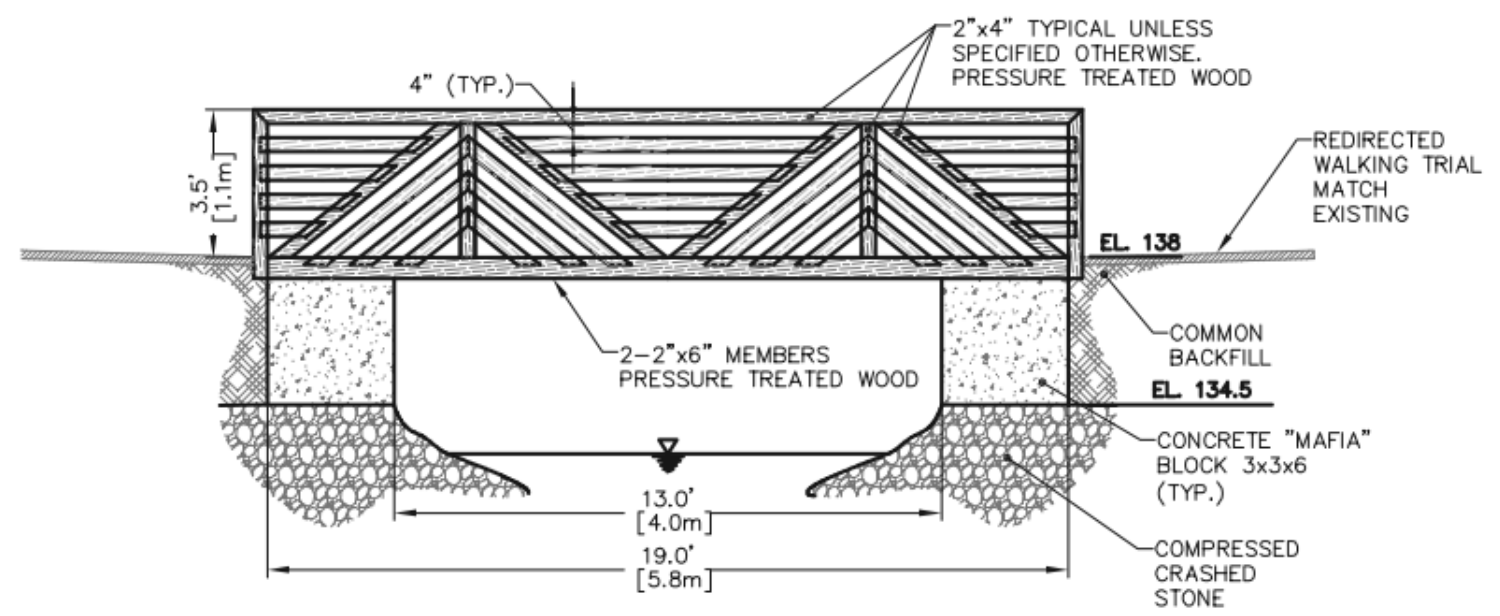

INITIAL RAILING SYSTEM DESIGN - WOOD BRIDGE ELEVATION NOT TO SCALE

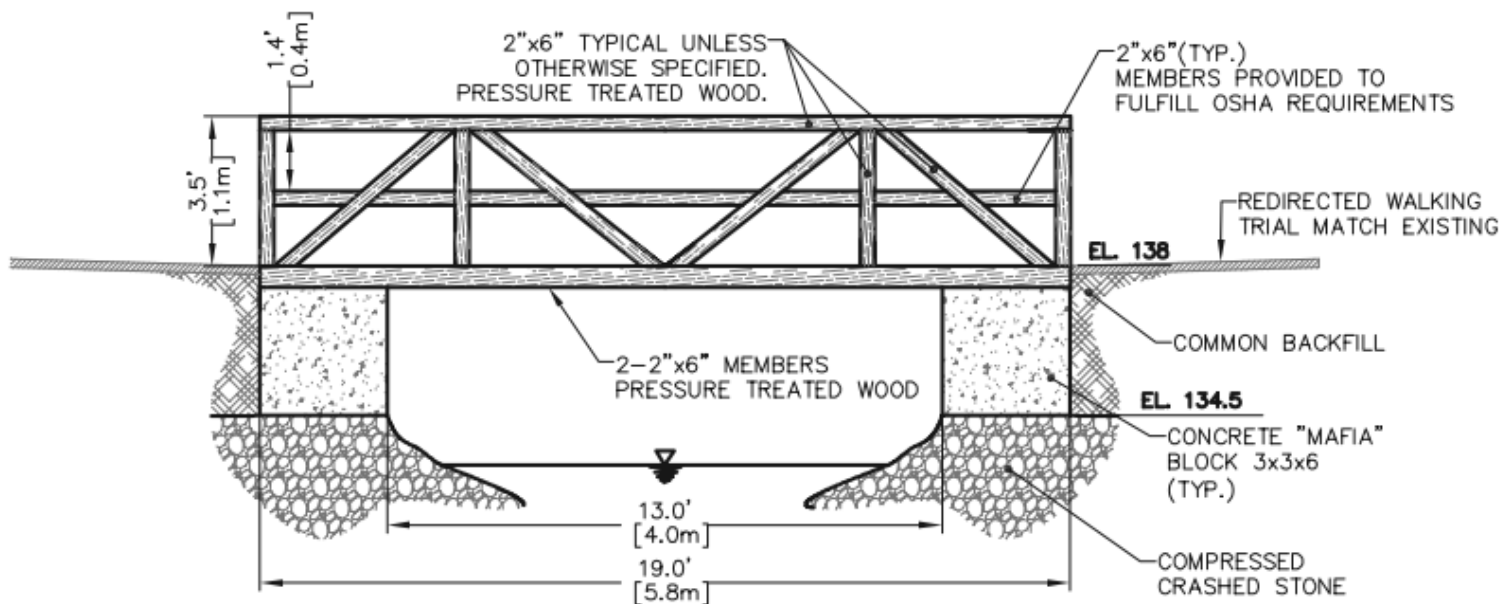

FINAL RAILING SYSTEM DESIGN - WOOD BRIDGE ELEVATION NOT TO SCALE

Figure 3: Initial and Final Railing System Designs 


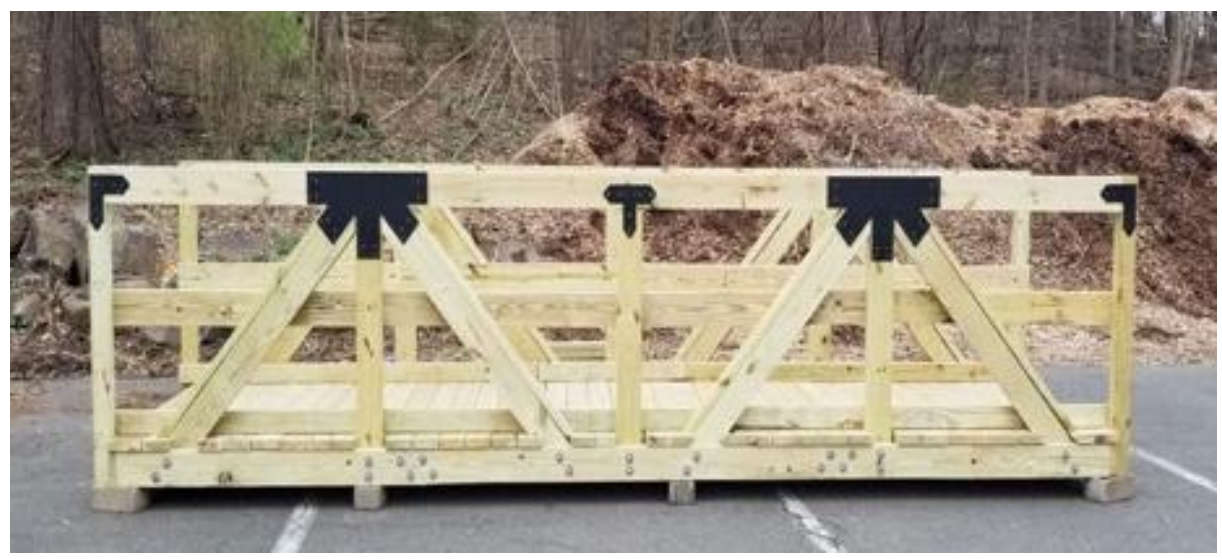

Figure 4: Timber Bridge

This senior project demonstrated challenges in complying with both competition rules and various design manuals under time and budget constraints. It is critical that participating students work closely with knowledgeable professors and mentors in the industry, as well as the client to deliver a satisfactory final product.

\section{Community Engagement}

The second objective of this senior project was to reach out to local communities and put the bridge into actual use. Various towns around the university and close to students' homes were contacted to find a "home" for the bridge. It took the team close to two months to find a town who was willing to work with college students and a site that was suitable based on competition guidelines.

This stage involved the highest level of uncertainty throughout the entire project duration, but proved to be meaningful and rewarding. First, the community engagement element greatly increased the complexity of this senior project. For example, the project team needed to review and follow various design manuals, and conducted surveying of the site to determine bridge elevation.

Second, community engagement provided participating students with an opportunity to interact with outside agencies and learn what it takes to deliver a project in real life. Two separate presentations were given at a Town Council meeting and a Parks and Recreation Commission meeting to obtain proper approvals and solicit input from the client. The team also communicated with the director of the Community, Recreation and Park Services throughout the entire senior project, building a strong partnership that leads to future collaboration opportunities. Another senior project team is currently working with the same town to build a pedestrian timber bridge for a public golf course, thanks to the professional and impressive work done by this project team.

Last but not least, the project team gained a sense of achievement when the bridge was open to the public and will continue to serve a local community in many years to come. On 
behalf of the Town, Parks and Recreation Department as well as the Parks and Recreation Commission, the director of the Community, Recreation and Park Services wrote a heartwarming thank you letter to the project team, the faculty advisor, and the President of Central Connecticut State University. An excerpt from the thank you letter reads: "These 5 students worked together and constructed and delivered a beautiful bridge for a very popular pond here. They have been absolutely fantastic to work with and extremely professional and dedicated. We thoroughly enjoyed the partnership we have made with CCSU and I have met with Dr. Zhou to discuss further opportunities to maintain our community engagement." Figure 5 shows the previously existing bridge and the new bridge delivered by the project team, demonstrating significant improvements to this pedestrian bridge over a small brook in a park.
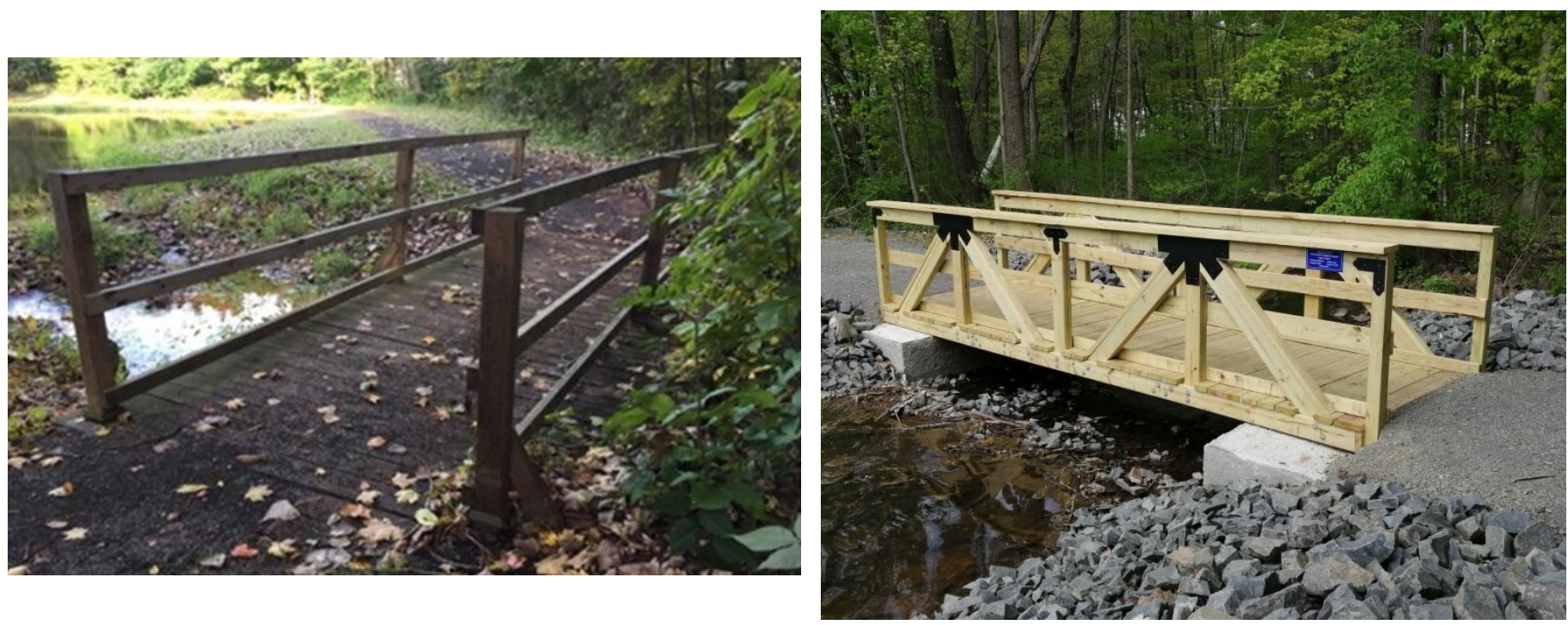

Figure 5: The Previously Existing Bridge and the New Bridge

\section{Funding and Schedule}

A unique aspect of this senior project was to actively seek external and internal funding. This project required a substantial amount of expenses; it was the first among around a hundred senior projects since the establishment of an ABET accredited CE program at CCSU. Although the department committed to supporting this project, it was made clear during the project proposal phase that the team needed to seek additional funding resources to supplement department funds.

Immediately after five students voluntarily teamed up and committed to this senior project, a Faculty Student Research Grant proposal was submitted and later the maximum allowable amount of $\$ 1,000$ for a team project was awarded. Several solicitation letters were sent to team members' families/friends and their employers. Fuss \& O'Neill, who hires one team member part-time, donated $\$ 500$. A GoFundMe page collected about $\$ 500$ and the department paid remaining expenses, which were approximately $\$ 400$. A grand total of $\$ 2,400$ was used to 
purchase materials and a donation plaque, transport the bridge to its site, and prepare competition shirts for the team.

As part of the Faculty Student Research Grant work, the project team studied different types of wood and compared their mechanical properties, durability, availability, and cost. Based on this research work, grade 1 and 2 dense, pressure-treated southern yellow pine was chosen. The project team also investigated different software packages that allow for structural analysis. IES Visual Analysis was used in the final design due to its readily available wood database.

The biggest challenge of this senior project was time constraints. As mentioned in the Introduction, all team members had other personal and professional commitments to maintain throughout the entire project. It was critical that each team member managed time efficiently and communicated regularly with other members in terms of progress made and difficulties encountered. At the same time, the whole team stayed highly agile and adaptive under the leadership of a faculty advisor and a student "captain", so additional manpower and resources were quickly allocated when necessary. The project schedule evolved over time, but major milestones were kept roughly as originally planned. Figure 6 shows the project timeline.

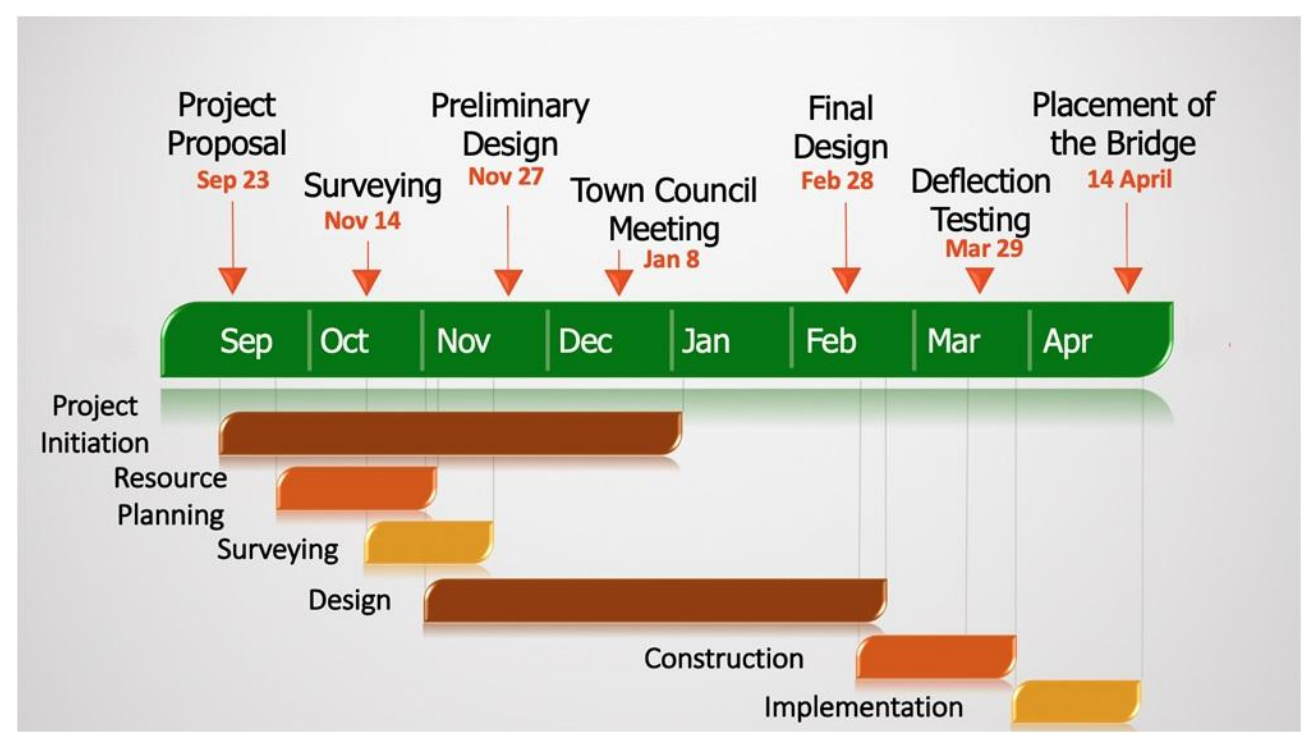

Figure 6: Project Timeline

\section{Assessment of Student Learning}

Systematic and formative assessment enhances student learning and yield academic gains [2]. Many prior studies documented instruments and strategies to assess student learning in capstone engineering design courses, see [3], [4], [5], [6], [7], [8] and [9]. Some studies ([5], [6], and [7]) focused on Mechanical Engineering or Electrical/Computer Engineering capstone projects, and a handful ([8] and [9]) were dedicated to the Civil Engineering discipline. While 
tools used in assessing this senior project are somewhat different from those presented in prior studies, the overall assessment structure is very similar, because most engineering programs need to demonstrate attainment of ABET student outcome using capstone design courses. Since the establishment of a CE program at CCSU about ten years ago, systematic assessment tools have been gradually developed and applied to evaluate senior projects, including bi-weekly personal progress logs, bi-weekly project time records, oral presentations, project posters, final project reports, and confidential peer review \& self-assessments.

In the bi-weekly personal progress logs, each team member listed specific tasks and assignments he/she personally completed in the last two weeks and identified specific tasks or assignments expected to be completed in the following two weeks. In the bi-weekly project time records, each team member entered the number of hours each day that were spent on different project tasks. These two assessment tools were designed to check on team progress as well as individual contributions. The faculty advisor collected these two documents every other week and addressed specific issues when necessary.

All eleven senior project teams delivered an oral presentation to the entire class at the end of the fall semester and again at the end of the spring semester to the class as well as invited guests (such as CE faculty, project mentors, and CE program advisory board members). Peer evaluation by the rest of the class was solicited using pre-distributed oral presentation scoring rubric. Faculty advisors who were responsible for entering course grades determined the proper weights for such student evaluations.

Since senior projects lasted two semesters, project reports at the end of the fall semester were graded based on problem/issue definition, engineering standards, constraint consideration, development of alternative solutions/designs, and a project plan. Final project reports at the end of the spring semester summarized all aspects of the project, and were evaluated based on selection of alternatives, detailed engineering design, implementation and construction (if applicable), and deliverables/engineering project documents, in addition to the elements expected in the fall semester report. Project posters were required upon completion of senior projects and were printed on 24 " by 36 " boards.

After oral presentations at the end of the spring semester, each team member completed a confidential peer review \& self-assessment. Each team member was asked to estimate the percentage of total contributions that he/she and the other team members made, name the person who was the team leader, name the person who had the greatest contribution to the final report and oral presentation, respectively, and identify the project phases/elements that were primary responsibilities for him/her and other team members. In addition, each student was asked to rank the top three senior projects in the entire class. This assessment tool supplemented the bi-weekly personal progress logs and bi-weekly project time records, and the faculty advisor assigned proper weights for this assessment tool in grade determination. Table 1 summarizes the assessment results for all five team members from the faculty advisor, using a scale of 10 . 
Table 1: Assessment Results for All Team Members

\begin{tabular}{|l|c|c|c|c|c|}
\hline & Student 1 & Student 2 & Student 3 & Student 4 & Student 5 \\
\hline Bi-weekly Personal Progress Logs & 9 & 8 & 8 & 6 & 10 \\
\hline Bi-weekly Project Time Records & 9 & 8 & 9 & 7 & 10 \\
\hline Oral Presentation & 10 & 9 & 8 & 9 & 9 \\
\hline Project Report & \multicolumn{5}{|l}{} \\
\hline Project Posters & 9 & 8 & 8 & 7 & 10 \\
\hline Self-assessment & 8 & 7 & 7 & 5 & 10 \\
\hline Peer Review &
\end{tabular}

Through this senior project, the team members experienced many facets of a real Civil Engineering project for the first time, including project solicitation, surveying, structural design, structure testing, and construction management. Lessons learned by the participating students can better prepare them for more complex tasks in their future engineering careers. The lessons are summarized below to help other senior students who want to take on a similar capstone project.

- In the project initiation phase, create a realistic schedule with major tasks and milestones; pay special attention to the competition date because it has the least flexibility. When creating a schedule, assign tasks to specific team members and specify a different member for QA/QC.

- Communicate with team members regularly and professionally. When communicating through emails with faculty, town officials, and vendors, make sure to copy all team members, so everyone keeps up with project progress and other team members can quickly take over a task in case of another member's personal indisposition. Additionally, communicate with team members and the faculty advisor, if a task becomes overwhelming so the team can adjust task assignments and expectations before it is too late.

- Investigate the site location before surveying, and add additional time for the surveying task in case weather conditions prove to be challenging to work in. Bring spare equipment or different equipment.

- Structural design is the center piece of this project, and it is an iterative process, requiring about 100 to 150 hours. Begin the design with a simple concept; make sure it follows basic structural design rules, then build up the complexity of the structure. Schedule additional time for QA/QC of the structural design. Assigning a person that did not create the design model is ideal since people often overlook simple mistakes made by oneself.

- Schedule structural design critiques with faculty advisors and mentors. During these meetings, the main goal is to align different design components with each other. For example, when designing a pedestrian timber bridge, deck structure design and railing design need to be compatible, and main wooden structure and connections need to work together. 
- Find a mentor with wood construction experience. Most CE curricula don't offer any training in wood construction. An experienced construction mentor makes the construction phase much more time effective and enjoyable. If such a mentor is unavailable, watch as many woodworking tutorials as possible before construction.

- In the construction phase, check dimensions and measurements twice before cutting materials, and again before installation. The project team cut several truss members half inch short, which was not discovered until the installation of rail grips. This caused not only material waste but also delays in construction.

- When testing the bridge, which does not allow for a second attempt according to competition rules, do a "dry run" test to familiarize all team members with the proper procedure and task assignments. In addition, take pictures of testing setups, gauges, and tape measurements so result readings can be confirmed by photos if necessary.

- The most important lesson learned that was already emphasized several times is to account for delays. Delays in order errors and material deliveries, or delays caused by weather (especially during winter months) will happen, and it is best to anticipate these from the start of a project. In addition, for a pedestrian timber bridge about 20 -ft long and a team without any experiences in wood construction, plan to accommodate for a 2-3 week delay in the construction phase.

Since the establishment of our ABET accredited CE program, students and faculty have finished about one hundred capstone projects. This was the first one that combined a design build project and a competition. It brought excitement and challenges to both the participating students and the faculty advisor. A few lessons learned from the faculty perspective are listed below.

- Student leadership has proven to be important to the overall success of a complex capstone project and to the satisfaction of participating students. The high demand with time commitment might be daunting to students if they are not motivated by a peer, who is working alongside and encouraging them. Depending on the dynamics among participating students, the faculty advisor may need to step in to "promote" a student captain. Technical knowledge is not critically important for a student captain, but a person with a strong technical background can be more convincing when different opinions on a task are raised.

- A complex capstone project normally requires different technical skill sets, and a single faculty member may not be able to efficiently advise students on all these aspects. Therefore, the faculty advisor needs to help students build a supportive environment by identifying and securing technical supports and advising mentor(s). At the same time, the faculty advisor needs to follow up with the team on advice they received and, when necessary, to step in and make a decision on behalf of the team. For example, when a mentor gives unrealistic 
guidance, the faculty advisor needs to communicate directly with the mentor and seek a balance between what the mentor suggests and what the team can accomplish.

- Timely and frank communications with students are important, especially when one or two team members become less motivated and fall behind in their assigned tasks. For a complex project, time is relatively tight; repetitive delays from one team member can jeopardize progress of the entire project and cause resentment among team members. If a team member chooses to contribute less, it is a good idea to explain to him/her and the whole team that their grades are dependent on their contributions, so other hard-working members will stay motivated, leading to successful completion.

\section{Conclusions}

The timber bridge senior project is a new capstone to the CE program at Central Connecticut State University, requiring an innovative approach to project management from participating students as well as advising faculty. The senior project has a national competition component and involves community engagement. Some parts of this senior project are not traditionally seen in other capstone projects in a relatively new ABET accredited CE program, such as fundraising and budgeting funds, coordinating with outside agencies, and constructing a pedestrian timber bridge following multiple sets of design criteria.

This senior project proved to be more challenging and time-consuming than expected, but the team completed it with dedication and professionalism and found it extremely rewarding upon completion. The team won second place in the Most Aesthetic Design category of the 2019 National Timber Bridge Design Competition, and received a heart-warming thank you letter from the town who received the donation. Moreover, this capstone project initiated a mutually beneficial partnership between the university and a local community, and opened the door for future collaborations.

A group of five students spent about eight months and approximately $\$ 2,400$ to design, build and test a 20-ft long pedestrian timber bridge, with the help of three faculty members and two industry mentors. Time management and teamwork were paramount to the success of this senior project, and leadership from a student "captain" was an important addition to the roles of faculty advisor and industrial mentors. Student learning through this senior project was assessed using a series of tools, including bi-weekly personal progress logs, bi-weekly project time records, oral presentations, project posters, final project reports, and confidential peer review \& self-assessments. As expected, almost all graduating students rated this senior project as the top one in their confidential peer review \& self-assessments.

Through this senior project, team members experienced many facets of a real Civil Engineering project for the first time, and learned many important lessons that would be beneficial in their future careers. For example, a realistic schedule and professional communication keep the team on track; QA/QC by other team member(s) and design critiques 
with faculty advisors and mentors ensure project quality; a "dry run" is very important when a second attempt is not allowed, so everyone is familiar with the proper procedure and task assignments during testing; for a complex senior project, delays will happen and it is the best to anticipate them from the start. This senior design project is one of the most essential and defining components of participating students' college education, and their experience will hopefully inspire future students to complete their degrees with meaningful and memorable capstone projects.

\section{Acknowledgement}

We sincerely thank our team members, Audrey Troch, Fernanda DeOliveira, Jennifer Ventura, and Kristjana Kabilo for their significant contributions to this senior design project. We also wish to thank Dr. Clifford Anderson, Mr. Gregory Dufel, Dr. Young moo Sohn, Mrs. Di Wu, Mr. Colin Dempsey, and Mr. John Doody for their guidance and help.

\section{References}

1. National Timber Bridge Design Competition http://southwest.msrcd.org/timberbridge/

2. P. Black and D. Wiliam, "Assessment and classroom learning," Assessment in Education, 5(1), pp 7-74, 1998.

3. D. Davis, S. Beyerlein, O. Harrison, P. Thompson, P., and M. Trevisan, "Assessments For Three Performance Areas In Capstone Engineering Design," Proceeding of the 2007 American Society for Engineering Education Annual Conference \& Exposition, Honolulu, HI, USA, June 24-27, 2007.

4. C. Schramm and A. Chan, "Capstone Project Evaluation - Towards a Student-Centred Approach," Proceeding of the 2013 Canadian Engineering Education Association Conference, Montréal, Québec, Canada, June 17-20, 2013.

5. D. Meyer, "Capstone Design Outcome Assessment: Instruments for Quantitative Evaluation," Proceedings Frontiers in Education 35th Annual Conference, 2005.

6. S. Laguette, "Assessment of Project Completion for Capstone Design Projects," Proceeding of the 2012 American Society for Engineering Education Annual Conference \& Exposition, San Antonio, TX, USA, June 10-13, 2012.

7. I. Damaj and J. Yousafzai, "Effective Assessment of Student Outcomes in Computer Engineering Programs using a Minimalistic Framework," International Journal of Engineering Education, 35, pp 59-75, 2019.

8. C. Quadrato, and R. W. Welch, "Grading Capstone Design: On Time and On Target," Proceeding of the 2003 American Society for Engineering Education Annual Conference \& Exposition, Nashville, TN, USA, June 22-25, 2003.

9. M. Bronzini and M. Casey, "Simulating Consulting Engineer Relationships in a Senior Design Course and Assessing the Results," Proceeding of the 2008 American Society for Engineering Education Annual Conference \& Exposition, Pittsburgh, PA, USA, June 22$25,2008$. 